\title{
European climate optimum and enhanced Greenland melt during the
} Last Interglacial

\author{
Maria Fernanda Sánchez Goñi ${ }^{*}$, Pepijn Bakker², Stéphanie Despratt ${ }^{1}$, Anders E. Carlson³, Cédric J. Van Meerbeeck², \\ Odile Peyron ${ }^{4}$, Filipa Naughton ${ }^{1,5}$, William J. Fletcher ${ }^{1,6}$, Frédérique Eynaud ${ }^{1}$, Linda Rossignol ${ }^{1}$, and Hans Renssen ${ }^{2}$ \\ ${ }^{1}$ EPHE, UMR-CNRS 5805 EPOC, Université Bordeaux 1, Avenue des Facultés 33405 Talence, France \\ 2Department of Earth Sciences, Section Climate Change and Landscape Dynamics VU, University of Amsterdam, Amsterdam, \\ Netherlands \\ ${ }^{3}$ Department of Geoscience and Center for Climatic Research, University of Wisconsin-Madison, Madison, Wisconsin 53706, USA \\ ${ }^{4}$ Laboratoire de Chrono-Environnement, UMR-CNRS 6249, Université de Franche-Compté, Besançon, France \\ ${ }^{5}$ Laboratorio Nacional de Geologia e Energia, LNEG, Unidade de Geologia Marinha, Aptdo 7586, 2721-866 Amadora, Portugal \\ ${ }^{6}$ Department of Geography, School of Environment and Development, University of Manchester, Manchester M13 9PL, UK
}

\begin{abstract}
The Last Interglacial climatic optimum, ca. $128 \mathrm{ka}$, is the most recent climate interval significantly warmer than present, providing an analogue (albeit imperfect) for ongoing global warming and the effects of Greenland Ice Sheet (GIS) melting on climate over the coming millennium. While some climate models predict an Atlantic meridional overturning circulation (AMOC) strengthening in response to GIS melting, others simulate weakening, leading to cooling in Europe. Here, we present evidence from new proxy-based paleoclimate and ocean circulation reconstructions that show that the strongest warming in western Europe coincided with maximum GIS meltwater runoff and a weaker AMOC early in the Last Interglacial. By performing a series of climate model sensitivity experiments, including enhanced GIS melting, we were able to simulate this configuration of the Last Interglacial climate system and infer information on AMOC slowdown and related climate effects. These experiments suggest that GIS melt inhibited deep convection off the southern coast of Greenland, cooling local climate and reducing AMOC by $\sim 24 \%$ of its present strength. However, GIS melt did not perturb overturning in the Nordic Seas, leaving heat transport to, and thereby temperatures in, Europe unaffected.
\end{abstract}

\section{INTRODUCTION}

The Last Interglacial (LIG; ca. 130-116 ka) represents the most recent period when North Atlantic summer climate was significantly warmer than present (Overpeck et al., 2006), and sea level was 4-9.4 m higher than today (Kopp et al., 2009). This sea-level highstand implies substantial melting of the Greenland Ice Sheet (GIS) (Northern Hemisphere ice volume is very likely to have shrunk by $\leq 2.6 \mathrm{~m}$ of equivalent sea-level volume when the loss of Arctic glaciers and ice caps is included; Otto-Bliesner et al., 2006; Colville et al., 2011) and Antarctic ice sheets (Kopp et al., 2009), suggesting a potential analogue for understanding the impact of ongoing global warming (Overpeck et al., 2006). Geochemical and magnetic runoff records from off the coast of south Greenland suggest elevated ablation and extensive GIS retreat through the LIG (Colville et al., 2011; Carlson et al., 2008); pollen concentration data indicate rapid colonization by shrub tundra following ice retreat (de Vernal and HillaireMarcel, 2008). This past retreat of ice sheets under a climate warmer than present allows insights into the effects of future GIS meltwater on the Atlantic meridional overturning circulation (AMOC) response and subsequent climate feedbacks. In the near surface, the AMOC transports warm and saline waters poleward across the North Atlantic, along wind- and density-driven currents. When cooling has made the waters sufficiently dense, deep convection with heat release to Europe can occur, after which the dense water masses flow equatorward as North Atlantic Deep Water. Although climate models do not show a consistent AMOC response to

*E-mail: mf.sanchezgoni@epoc.u-bordeaux1.fr.
GIS melting (e.g., Fichefet et al., 2003; Jungclaus et al., 2006; Lunt et al., 2004; Swingedouw and Braconnot, 2007), they generally simulate North Atlantic and European cooling in response to increased freshwater forcing to the North Atlantic and the attendant reduction in AMOC strength (Stouffer et al., 2006). In contrast, the LIG was characterized by maximum development of temperate forests in Europe, the so-called Eemian interglacial, with estimated summer temperatures $\sim 2{ }^{\circ} \mathrm{C}$ warmer than present (Kaspar et al., 2005), suggesting that the warmest LIG regional climate occurred during a period of GIS retreat. Here, we provide new insights into the impact of GIS melting on the AMOC and western European climate during the LIG.

\section{METHODS}

We present new high-resolution marine and terrestrial paleoclimatic data from a marine sediment core retrieved in the Bay of Biscay; core MD04-2845 (Sánchez Goñi et al., 2008) (Fig. 1) spans ca. 140 ka to the present. This sequence allows the establishment of a direct correlation between records of European vegetation and climate, sea-surface temperature (SST), ocean ventilation variability, and iceberg discharges, precluding the potential chronological uncertainties involved in comparing paleoclimatic records from different sites (for detailed methods, age model construction, pollen percentage diagram, and quantitative climatic reconstruction, see Figs. DR1-DR4 and Table DR1 in the GSA Data Repository $^{1}$ ). These records are compared through a common age model (Table DR1) with records from the Eirik Drift off southern Greenland documenting the response of the GIS (Carlson et al., 2008) (Fig. 2). Relative changes in southern GIS ablation are reconstructed through documenting the concentration of terrestrially derived elements (i.e., Ti) in Eirik Drift sediment. For example, increased Ti deposition reflects increased sediment discharge from Greenland and thus greater runoff from ablation (Carlson et al., 2008); this has recently been further confirmed though radiogenic isotope tracing of Eirik Drift silt-sized sediment (Colville et al., 2011). To evaluate the physical consistency of our proxy-based inferences, we also investigated the impact of enhanced GIS melt on the AMOC and European temperatures with a global climate model. A full description of the simulations was provided in Bakker et al. (2011) (and in Table DR2 and Fig. DR5).

\section{RESULTS AND DISCUSSION}

After the millennial-scale ice-rafting event (Heinrich event, HE 11) (Shackleton et al., 2003) documented by a prominent ice-rafted debris (IRD) peak at $135 \pm 2 \mathrm{ka}$ in deep-sea core MD04-2845, the penultimate deglaciation was marked by a particularly strong and rapid warming in

${ }^{1}$ GSA Data Repository item 2012185, detailed methods, age model construction, pollen percentage diagram, quantitative climatic reconstruction, and description of the simulations, is available online at www.geosociety.org/pubs /ft2012.htm, or on request from editing@geosociety.org or Documents Secretary, GSA, P.O. Box 9140, Boulder, CO 80301, USA. 